\title{
DIREITO À AUTODETERMINAÇÃO INFORMATIVA NO MERCADO DE CRÉDITOS: ANÁLISE ECONÔMICA DO CADASTRO POSITIVO DE DADOS NO RESP 1419697/RS
}

\author{
RIGHT TO INFORMATIONAL SELF-DETERMINATION IN THE CREDIT \\ MARKET: ECONOMIC ANALYSIS OF THE POSITIVE DATA LIST IN RESP \\ 1419697 / RS
}

\author{
${ }^{1}$ Hian Silva Colaço \\ ${ }^{2}$ Carolina Vasques Sampaio
}

\section{RESUMO}

O cadastro positivo de dados permite a redução dos custos de transação e facilita o acesso ao crédito, contudo pode limitar o controle sobre o fluxo informacional, representando uma ameaça ao exercício do direito à autodeterminação informativa. Para tanto, indaga-se acerca da possibilidade de harmonização entre o direito ao acesso à informação e à privacidade, tomando como base a decisão paradigmática no REsp no 1419697/RS, que reconheceu a legalidade do sistema "credit scoring". Constatou-se que é possível conciliar o exercício da autodeterminação informativa no mercado de créditos, desde que o cadastro positivo respeite às regras de proteção de dados.

Palavras-chave: Direito à autodeterminação informativa, mercado de créditos, assimetria de informação, cadastro positivo, análise econômica do direito.

\begin{abstract}
The positive data list allows the reduction of transaction costs and facilitating access to credit, but can limit the control over the information flow, posing a threat to the exercise of the right to informational self-determination. Therefore, it asks about the possibility of harmonization between the right to access to information and privacy, based on the paradigmatic decision REsp No. 1419697 / RS, that recognized the legality of the system "credit scoring". It was found that it is possible to reconcile the exercise of informational self-determination in the credit market, since the positive list respects the data protection rules.
\end{abstract}

Keywords: Right to informational self-determination, credit market, information asymmetry, positive data list, law and economics.

\footnotetext{
${ }_{1}^{1}$ Mestrando em Direito Constitucional pela Universidade de Fortaleza - UNIFOR, Ceará, (Brasil). Pesquisador na Área de Direito Civil-Constitucional, Direitos de Personalidade, Responsabilidade Civil e Direito Digital. E-mail: hiancolaco@hotmail.com

${ }^{2}$ Mestranda em Direito Constitucional pela Universidade de Fortaleza - UNIFOR, Ceará, (Brasil). Integrante do Grupo de Pesquisa - Cnpq em Direito Constitucional nas Relações Privadas. E-mail: carolinavasques@ gmail.com
} 


\section{INTRODUÇÃO}

A Sociedade da Informação (CASTELLS, 2005) qualifica-se pelo esgarçamento das fronteiras existentes entre o espaço público e privado, em torno da modelagem do fluxo informacional. As informações colocam-se como valioso bem jurídico e econômico, utilizadas como instrumento de afirmação da personalidade e, simultanemente, produção de riquezas.

Os perfis informacionais passam a definir quem as pessoas são no meio virtual, moldam grande parcela das relações sociais por elas travadas e apresentam-se como combustível dos conflitos existentes na sociedade da informação digital. Por isso, faz-se necessário o Direito desincumbir-se do papel de regular as celeumas protagonizadas na modernidade líquida (BAUMAN, 2008).

O direito à privacidade, assim, impõe-se como um direito fundamental e de personalidade extremamente vulnerável no meio virtual. A feição desse direito evoluiu a partir de uma concepção estática, focada no direito de "estar só" (WARREN; BRANDEIS, 1890), para a tutela dinâmica, concretizada no direito à autodeterminação informativa, ou seja, na faculdade conferida a cada pessoa para construir livremente a sua esfera privada no contexto da sociedade informacional (RODOTÀ, 2008).

Nesse sentido, a capacidade de controlar o fluxo informacional ganhou expressivo relevo na contemporaneidade, elevando a temática da proteção de dados pessoais ao epicentro das preocupações do século XXI, fato este que ensejou regulamentação própria da referida temática em diretiva da União Europeia.

Essa nova realidade implicou na proliferação dos bancos de dados pessoais, utilizados pela Economia como instrumentos de correção das falhas de mercado, advindas da assimetria de informações. Quanto maior o fluxo informacional disponível, melhores serão as condições de obtenção de crédito e, consequentemente, haverá mais desenvolvimento econômico e social. Por isso, relevante a aferição da racionalidade econômica presente nos bancos de dados de informações negativas e positivas.

Dessa maneira, objetiva-se analisar os impactos do exercício do direito à autodeterminação informativa no mercado de créditos, especificamente quanto à experiência adotada com a utilização dos cadastros positivos de dados. Averigua-se, se é possível a harmonização entre o direito ao livre acesso à informação e o direito à privacidade, tomando 
como base a decisão paradigmática no Recurso Especial no 1419697/RS, que reconheceu a legalidade do sistema "credit scoring".

A metodologia utilizada na elaboração da pesquisa segue uma abordagem qualitativa, descritiva e exploratória, no que toca aos objetivos; bibliográfica quanto ao tipo; pura, quanto ao manejo dos resultados, colhidos a partir de um estudo descritivo-analítico, desenvolvido por meio de pesquisa teórica, em que se propôs o diálogo entre a metodologia do direito civilconstitucional e a análise econômica do direito.

\section{DIREITO À AUTODETERMINAÇÃO INFORMATIVA E OS NOVOS CONTORNOS DA PROTEÇÃO À PRIVACIDADE NA SOCIEDADE DA INFORMAÇÃO}

O avanço da tecnologia informacional gerou um processo de hibridização espacial das relações sociais, pois os indivíduos adaptaram-se a viver conectados e, por conseguinte, divididos entre o universo palpável e o virtual. Fala-se em uma sociedade monitorada, panoptizada, confessional, na qual as fronteiras entre o público e o privado estão esgarçadas e quem não se inserir no meio digital estará desabilitado socialmente (BAUMAN, 2008, p. 25).

Ao passo que o progresso tecnológico e as ferramentas virtuais tenham sido capazes de democratizar o acesso ao conhecimento e à informação, também trouxeram inúmeras modalidades de conflitos a serem solucionados pelo Direito, pois esse novo espaço torna vulnerável a esfera privada, ensejando, consequentemente, violações a direitos da personalidade, dentre os quais se destaca o direito à privacidade.

Nesse contexto intitulado de Sociedade da Informação (CASTELLS, 2005), esta apresenta-se como matéria-prima da Revolução Tecnológica, assumindo papel de bem econômico (MURRAY, 2010, p.4) e elemento estruturante das relações sociais praticadas no meio virtual.

Diante da ascensão dos bens imateriais como importante fator de desenvolvimento econômico e social, fala-se atualmente em "mercado de informação" (GONÇALVES, 2003, p. 129), "economia da informação" (BRAMAN, 2011, p. 47). Conquanto, o novo paradigma tecno-econômico da tecnologia informacional supera o tradicional modelo fordista cujos 
fatores de produção eram bens materiais (LASTRES, 2011, p. 47), elevando a informação como meio dominante do tráfego econômico.

Com efeito, numa sociedade globalizada, de massa e voltada para o consumo, o manejo de dados de conteúdo estratégico tornou-se meio determinante de organização dos atores no cenário econômico. Ao estabelecer-se uma comunicação produtiva capaz de precificar ou monetizar a informação, será possível prever o comportamento dos consumidores em esfera global (MATTOS, 2012, p. 147). Daí, evidencia-se o controle informacional como instrumento de poder.

Ademais, os dados de conexão disponibilizados no meio digital são bastantes vezes utilizados para traçar perfis pessoais de consumidores, com o propósito de publicidade. Diante disso, o acesso refinado às preferências pessoais, tendências de compras e gostos dos consumidores obtidos em razão de suas informações disponibilizadas em rede tornam essa valiosa mercadoria um bem econômico (PEZELLA; GHISI; 2015, p. 18).

$\mathrm{Na}$ medida em que tal valor jurídico consolida-se como instrumento de distribuição de riquezas e combustível do progresso econômico, não é legítima a extração desse potencial de forma ilimitada, sob pena de violação de inúmeros outros valores correlatos de igual importância para a ordem jurídica. Por isso, deve o Direito imiscuir-se na tarefa de regular os limites na utilização das informações como bem econômico, de modo a impedir ofensas a direitos de personalidade.

O exercício desmesurado do direito de informar e ser informado, assim como a plena liberdade no manuseio das informações, no meio virtual, configuram-se como meios de lesar o direito à privacidade, este fundamental, e de personalidade especialmente merecedor de tutela no contexto da Sociedade da Informação.

Historicamente, a construção do direito à privacidade assentou-se na perspectiva de uma liberdade negativa, mediante a concepção de que o titular de tal direito não deveria sofrer interferências de terceiros em seu espaço de intimidade (MENDES, 2012, p. 282/283). A confirmar, apresenta-se a ideia de intimidade como a faculdade de reservar-se ao claustro, ao abrigo da multidão, recolhido ao castelo, própria da terminologia do direito de "estar só"(WARREN; BRANDEIS, 1890).

Contudo, tal perspectiva de proteção da privacidade como inviolabilidade do manto privado mostrou-se insuficiente, frente à nova textura social evidenciada na sociedade 
informacional, de modo a reclamar uma tutela dinâmica (RODOTÀ, 2008, p. 17) ou plural (LEONARDI, 2012, p. 78/90) atinente ao "controle da coleta e da utilização dos próprios dados pessoais" - liberdade positiva (SCHREIBER, 2011, p. 131).

Além do mais, as informações constituem um dos bens jurídicos mais valiosos. Dessa forma, a capacidade de controlá-las, traduz, concretamente, a aquisição de um "poder sobre si mesmo" (MORAES, 2010, p. 58), inferindo-se daqui a sua correlação com o direito à privacidade. Justifica-se essa proteção especial, exatamente em razão da situação de vulnerabilidade da pessoa no meio virtual, dada às inúmeras informações de caráter pessoal circulam sobre ela, muitas vezes sem qualquer controle, na rede mundial de computadores.

Salienta-se, assim, que o indivíduo conectado passou a orientar suas ações, modelar a sua relação com os demais e delimitar seu espaço de convivência a partir das informações as quais recebe e produz (DONEDA, 2015, on-line). Diante disso, o armazenamento, o manuseio e a exploração econômica das informações pessoais ascenderam como meio de controlar as preferências e influir na tomada de decisões dos sujeitos on-line, rememorando, muitas vezes, informações desatualizadas ou sem relevância.

Questiona-se o fato de esquecer informações, uma vez disponibilizadas em rede, terse tornado caro e difícil, enquanto lembrar é barato e fácil (MAYER-SCHÖNBERGER, 2009, p. 57). Portanto, indaga-se acerca do perigo desses dados pessoais ficarem armazenados "na rede como se fossem uma tatuagem, que nos seguirá pela vida toda" (CASTELLANO, 2012, p. 4).

Dessa maneira, o debate envolvendo a possibilidade de indisponibilizar a veiculação de informações inseridas na rede levou a formulação do chamado direito à autodeterminação informativa, consectário do direito à privacidade, na feição positiva; enquanto poder de controlar as informações pessoais em circulação na rede capazes de definir traços importantes da personalidade (CANOTILHO, 200, p. 500).

Defende-se, por conseguinte, a possibilidade de controle espacial, contextual e temporal dos dados, de modo a assegurar a proteção das escolhas pessoais, após certo período, momento o qual a pessoa não deseja mais ser relembrada por dados passados. Evolui-se da clássica noção de privacidade, centrada no trinômio "pessoa-informação-sigilo", para a tutela efetiva da "pessoa-informação-circulação-controle", ou seja, o desafio de controlar a obtenção, o tratamento e a transferência das informações as quais digam respeito ao 
indivíduo, de modo a permitir a livre construção de sua esfera privada (RODOTÀ, 2008, p. 94).

Nesse contexto, a pessoa não mais pode ser sujeito passivo na relação informacional, vítima da incontrolabilidade de seus dados, mas deve ser assegurada a possibilidade de examinar a exatidão, veracidade, finalidade, atualidade e análise temporal das informações, em rede, de modo a efetivar os corolários de tutela da dignidade da pessoa humana (GONÇALVES; SAMPAIO, 2013, p. 3).

Logo, o direito à autodeterminação informativa elevou-se como uma das principais fronteiras da tutela da privacidade na sociedade da informação digital, já tendo sido reconhecido expressamente pelo Tribunal Federal Alemão em 1983; assim como na Diretiva 95/46/CE da União Europeia, a qual prevê a facilitação do acesso, retificação, oposição e cancelamento dos dados pessoais no meio digital.

O consentimento do usuário de Internet, o respeito à legítima finalidade, assim como a definição do período de armazenamento das informações e obrigatoriedade de sua remoção, após expirado o prazo, são algumas diretrizes de gestão na rede estabelecidas pela Comissão Europeia.

Consoante o exposto, evidencia-se como tendência a problematização das questões atinentes à proteção da privacidade, no meio virtual, em torno da disciplina dos dados pessoais disponibilizados em rede. $\mathrm{Na}$ sua feição menos controvertida, o direito à autodeterminação informativa se manifesta na capacidade de excluir informações disponibilizadas pela própria pessoa no meio virtual, estendendo-se à possibilidade de indisponibilizá-las, após terem sido compartilhadas por terceiros e, finalmente, ao poder de controlar a veiculação de dados pessoais disponibilizados por terceiros (FLEISCHER, 2015, on-line).

Com o desiderato de garantir o controle espacial, contextual e temporal dos dados pessoais, a Organização para Cooperação e Desenvolvimento Econômicos (OCDE) lançou diretrizes relacionadas à proteção dos fluxos de dados, de modo a enfatizar a necessidade de observância aos princípios da transparência (publicidade); da qualidade; da finalidade; do livre acesso; da segurança física e lógica; e da proporcionalidade.

Tais princípios, ainda que fracionados, condensados ou adaptados, constituem a espinha dorsal de diversos instrumentos normativos de proteção de dados pessoais, por isso 
podem servir de instrumento para a solução de diversos problemas no ordenamento jurídico pátrio, o qual carece de uma lei específica ${ }^{3}$ capaz de concretizar o exercício do direito à autodeterminação informativa.

No tocante à possibilidade de utilização das informações pessoais por terceiros, insurge, $a b$ initio, a investigação sobre o critério do consentimento do titular, pois este é o elemento fundamental capaz de autorizar perfunctoriamente o tratamento de dados. Entretanto, tal critério apresentou-se insuficiente, pois, inúmeras vezes, embora tendo sido conferida a anuência, a finalidade precípua para a o manuseio dos dados não é preservada. Por isso, mostra-se relevante o respeito aos princípios anteriormente expostos, haja vista serem capazes de acolher a proteção de dados em momento posterior ao consentimento, ao assegurar o livre acesso, o direito à retificação e exclusão, à transparência e à finalidade.

Ainda no âmbito da concretização do direito à autodeterminação informativa, insurge o complexo tema acerca da proteção à categoria de dados sensíveis ${ }^{4}$, pertinentes à qualificação de aspectos personalíssimos do indivíduo, como suas preferências religiosas, políticas e filosóficas; orientação sexual; condição de saúde mental ou genética; dentre outros. A grande discussão reside em torno da possibilidade de veiculação desses dados, com o objetivo de repassá-los aos empregadores, plano de saúde e seguradoras.

A exploração econômica dessa espécie de dados é hábil a violar inúmeros valores merecedores de tutela, pois a transferência de dados sensíveis e o cruzamento de dados nãosensíveis capazes de produzir aqueles podem ensejar na obtenção de resultados discriminatórios, ofensivos ao princípio da dignidade da pessoa humana.

Conquanto, tal princípio encontra seu substrato material em quatro postulados, de modo a ser subdividido nos corolários da igualdade, integridade psicofísica, liberdade e solidariedade (MORAES, 2010, p. 85). Logo, a veiculação de dados sensíveis pode violar todos corolários do princípio da dignidade da pessoa humana, haja vista ser capaz de produzir

\footnotetext{
${ }^{3}$ Proposta que cria um marco regulatório para a proteção, o tratamento e o uso de dados pessoais dos brasileiros foi aprovada, no dia 13 de outubro de 2015, na Comissão de Ciência, Tecnologia, Inovação, Comunicação e Informática (CCT). Depois da realização de audiências públicas sobre o tema e da apresentação de 29 emendas pelos integrantes da comissão, o substitutivo do senador Aloysio Nunes Ferreira (PSDB-SP) ao Projeto de Lei do Senado (PLS) 330/2013 foi acatado e agora segue para as Comissões de Meio Ambiente, Defesa do Consumidor e Fiscalização e Controle (CMA), de Assuntos Econômicos (CAE) e de Constituição, Justiça e Cidadania (CCJ). ${ }^{4}$ A Diretiva 95/46/CE qualificou como sensíveis os "dados pessoais reveladores de origem racial ou étnica, opiniões políticas, convicções religiosas ou filosóficas, associação a sindicatos e o processamento de dados envolvendo a saúde ou a vida sexual”. Da mesma forma expõe o art. $3^{\circ}, \S^{\text {o }}$, II, da Lei n 12.214/2011.
} 
resultados discriminatórios (igualdade), limitar a liberdade em razão das constrições aplicadas por terceiros decorrente da divulgação das informações sensíveis, afetar a integridade psicofísica do indivíduo exposto e ferir a solidariedade ao condicionar o livre desenvolvimento das potencialidades humanas.

Em face da construção teórica exposta, percebe-se que a proteção dos dados pessoais, sejam eles sensíveis ou não, deve ser alvo de preocupação. Afinal, compram-se e vendem-se informações de modo indiscriminado, sem qualquer parâmetro ou limite. Quando a referida problematização volta-se para o mercado de crédito, insurge uma difícil tarefa ao jurista: como conciliar os valores estruturantes que justificam o direito à autodeterminação informativa com a necessidade de promover o desenvolvimento econômico e a facilitação do acesso ao crédito ?

De um lado, colocam-se os consumidores cujos dados pessoais armazenados em bancos de dados reclamam proteção diferenciada e de outro as instituições financeiras as quais necessitam das informações para fazer a análise eficiente de risco na concessão do crédito. A comum colisão entre a liberdade de acesso à informação e a proteção da privacidade, enquanto direito à autodeterminação informativa, apresenta-se como epicentro das investigações do presente trabalho, desenvolvido sob influxos das balizas oferecidas pela análise econômica do direito.

\section{ANÁLISE ECONÔMICA DOS BANCOS DE DADOS: REDUÇÃO DA ASSIMETRIA INFORMACIONAL， INIBIÇÃO DE COMPORTAMENTOS OPORTUNISTAS E FACILITAÇÃO DO ACESSO AO CRÉDITO}

A facilidade de acesso às informações disponíveis ao mercado de crédito vincula-se diretamente ao progresso econômico deste, por criar um clima propício aos negócios, aproximando-o da condição de mercado perfeito, quando o elevado fluxo de informações não permite a existência de falhas. (SEIDENFELD, 1996, p. 35). Assim, percebe-se que a quantidade de informações existentes no mercado e os custos de transações são fatores inversamente proporcionais. 
Desse modo, entende-se que a eficiência dos mercados de créditos está intrinsecamente ligada à existência de instrumentos os quais permitam a redução das assimetrias de informação, de modo a proporcionar uma melhor avaliação dos riscos de inadimplência do potencial tomador de crédito (TURNER, 2007).

Sabe-se que as instituições financeiras são as principais responsáveis pela concessão de crédito, e não há desenvolvimento econômico sem disponibilidade de crédito no mercado (SADDI, 2007, p. 282). Nesse sentido, o fenômeno da assimetria informacional ocorre quando tais instituições carecem de dados suficientes acerca dos possíveis tomadores de crédito, de modo a impedir uma análise eficiente do risco existente na concessão de financiamento ou empréstimo. Quanto maior a assimetria, mais altos serão os custos de transação, os quais serão internalizados por meio da cobrança de elevadas taxas de juros, com o desiderato de se resguardar perante prováveis comportamentos oportunistas (BADIN; SANTOS; DAMASO, 2007, p. 15).

Em um mercado imperfeito, repleto de falhas informacionais, os bons pagadores arcam com os altos encargos na concessão de crédito em razão da impossibilidade de diferenciá-los dos maus, fenômeno conhecido como seleção adversa, em que o mercado passa a selecionar adversamente os tomadores de crédito oportunistas, haja vista ser desinteressante ao bom tomador optar por financiamento com altos custos (MISHKIN, 2000).

Enquanto a seleção adversa é um comportamento oportunista pré-contratual, o risco moral apresenta-se, geralmente, como uma falha de mercado após a assunção do contrato de concessão de crédito. Este pode ser verificado enquanto informação oculta, quando o agente tomador esconde alguma informação desabonadora, no momento do financiamento, capaz de impedir a liberação do crédito; e ação oculta - ocasião na qual o contratante modifica o seu comportamento anterior - de modo a praticar ações escusas de alto risco não condizentes em quantidade e qualidade para as quais se propôs ao tempo da assunção da dívida (AZEVEDO, 1998).

Conquanto, as taxas de juros elevadas em razão da internalização dos custos de transação gerados pela assimetria informacional, ao passo que desencorajam os bons contratantes e selecionam os tomadores de maior risco, também estimulam estes a buscarem negócios mais arriscados, com o fito de compensar o respectivo aumento da taxa de juros (STIGLITZ; WEISS, 1981). 
Diante dos problemas apresentados, coloca-se como perspectiva de solução a ação conjunta entre demandantes e ofertantes no sentido de reduzir a assimetria de informações existentes, de modo a se obter um custo de crédito razoável para ambos. Tal realidade se concretiza com a disponibilização de informações negativas e positivas referentes às transações creditícias, anteriormente realizadas pelos tomadores, com o desiderato de oferecer uma eficaz mensuração do risco na concessão do crédito (BARRON; STATEN, 2003).

Nesse contexto, os modelos de compartilhamento de informações - negativas e, especialmente, positivas - representam as estruturas mais eficientes de análise da decisão de concessão de crédito. Com o estabelecimento de um filtro capaz de selecionar os bons e maus pagadores, tona-se possível oferecer taxas de juros personalizadas, de modo a corrigir as distorções de mercado supracitadas.

Dessa forma, percebe-se a relevância dos bancos de dados de proteção ao crédito como facilitadores do acesso, de baixo custo, às informações pelas instituições bancárias. No Brasil, dentre os sistemas de compartilhamento privados de informações eminentemente negativas têm-se o Serviço de Proteção ao Crédito (SPC) e a SERASA Experian.

Contudo, salienta-se que o acesso às informações somente negativas ou desabonadoras relacionadas à inadimplência não é hábil a corrigir todas as distorções originadas pela assimetria de informações. De posse, apenas de dados sobre a inadimplência dos clientes, os bancos não estariam habilitados a selecionar eficazmente os bons e maus pagadores, necessitando de dados relativos ao passado creditício desses (hábitos de pagamento), portanto, informações positivas.

Nesse sentido, no dia 9 de junho de 2011 a Lei ${ }^{\circ} 12.414$ fora sancionada, de modo a dispor sobre a formação de banco de dados com informações de adimplemento, o conhecido cadastro positivo. O referido cadastro colocou-se como um importante instrumento de sinalização do risco de crédito, pois a existência de um banco de dados mais completo dispondo de um vasto perfil dos consumidores acerca de seus pagamentos básicos, como água, luz e telefone - permitiu que pessoas até então excluídas do mercado do crédito pudessem obter excelentes taxas de financiamento com base em dados simples, mas de grande valia para a análise do risco.

Defende-se a ideia a qual a racionalidade econômica do cadastro positivo justificarse-ia na aplicação da Teoria dos Jogos, desenvolvida por John Nash, ao passo que a 
instituição financeira, diante da carência de informações, aumentaria as taxas de juros com o intuito de compensar eventual desonestidade do tomador de crédito. Noutro sentido, quando da existência de um cadastro positivo de dados, o elemento cooperativo expresso na sinalização do potencial de risco apresenta-se como fator determinante do comportamento da instituição, ao conceder melhores taxas para o acesso ao crédito (BARCELLOS, 2015, online).

Nessa perspectiva, a informação assume papel de bem econômico cuja importância se cristaliza no suporte à tomada de decisões de concessão de crédito, servindo como barganha das instituições financeiras aos tomadores de crédito - que as utiliza como critério diferenciador dos maus e bons pagadores - de modo a remover os obstáculos econômicos gerados pelo risco moral e pela seleção adversa.

Contudo, faz-se necessário observar, no compartilhamento das informações, as quais comporão o cadastro positivo de dados, as regras atinentes à proteção dos dados pessoais, pois a atividade de coleta desenvolvida apresenta-se como potencialmente lesiva à privacidade - na sua feição de direito à autodeterminação informativa - quando houver o compartilhamento de informações sem o consentimento do consumidor, a exploração de dados sensíveis deste e a manutenção infinita de uma anotação negativa ou até positiva.

Dessa forma, torna-se difícil a tarefa de harmonização entre o direito à autodeterminação informativa com o direito ao livre acesso à informação capaz de impulsionar o desenvolvimento econômico e social do país. Por isso, faz-se importante analisar algumas regras relativas à criação do cadastro positivo e a compatibilização dessas regras com o sistema de proteção aos dados pessoais, diante da análise do caso concreto evidenciado no Recurso Especial no 1419697/RS.

\section{DIREITO À AUTODETERMINAÇÃO INFORMATIVA NO MERCADO DE CRÉDITOS: NECESSÁRIA HARMONIZAÇÃO ENTRE A LIBERDADE DE ACESSO À INFORMAÇÃO E A PRIVACIDADE NO PARADIGMÁTICO RESP No 1419697/RS}

Tanto o direito à autodeterminação informativa quanto ao livre acesso à informação possuem limites, esses servem com o desiderato de harmonizar o exercício de ambos sem que haja uma supressão do outro. Dessa forma, não é possível a defesa de uma proteção exagerada 
aos dados pessoais, de modo a inviabilizar os ganhos com o desenvolvimento econômico e a redução das desigualdades sociais proporcionadas pela facilitação do acesso ao crédito com a utilização dos bancos de dados.

Assim como o sistema de compartilhamento de dados comandado por empresas públicas e privadas não pode exercer o tratamento dessas informações de modo indiscriminado, em desobediência aos limites legais trazidos pela Lei $n^{\circ}$ 12.414/2011, aos princípios gerais aplicáveis à proteção dos dados pessoais e aos ditames constitucionais que resguardam o núcleo essencial do direito à privacidade. Dessa forma, propõe-se a conciliação entre os valores igualmente merecedores de tutela no contexto da sociedade da informação: informação-privacidade.

Conforme explicitado, a Lei $\mathrm{n}^{\mathrm{o}}$ 12.414/2011 regulamentou o cadastro positivo de crédito no ordenamento jurídico pátrio, previndo expressamente ${ }^{5}$ a necessidade de adesão voluntária das pessoas físicas ou jurídicas, diferentemente do cadastro negativo. Desse modo, o dispositivo legal deixa claro a necessidade de consentimento formalizado do consumidor em potencial para integrar o cadastro positivo.

A adesão ao cadastro representa uma abnegação à parcela da privacidade de determinados dados, os quais poderão ser utilizados com o desiderato de oferecer melhores condições de acesso ao crédito; contudo, não representa uma renúncia a tal direito, pois a autodeterminação informativa ${ }^{6}$ deverá ser observada a todo momento, com o objetivo de impedir que as informações sejam utilizadas com finalidade diversa.

Nesse passo, uma das formas de expressão do direito à autodeterminação informativa mais próximas de um direito ao esquecimento no mercado de créditos seria a delimitação temporal da permanência das informações no cadastro positivo. Pertinente ao Cadastro

\footnotetext{
${ }^{5} \mathrm{O}$ art. $4^{\circ}$ da Lei $\mathrm{n}^{\circ}$ 12.414/2011 instituiu, in verbis: "a abertura de cadastro requer autorização prévia do potencial cadastrado mediante consentimento informado por meio de assinatura em instrumento específico ou em cláusula apartada".

${ }^{6} \mathrm{~A}$ Lei $\mathrm{n}^{\mathrm{o}} 12.414 / 2011$ previu, indiretamente, meios de exercer o direito à autodeterminação informativa, como se observa $\mathrm{n}$ art. $5^{\circ}$, in verbis: "são direitos do cadastrado: I - obter o cancelamento do cadastro quando solicitado;

II - acessar gratuitamente as informações sobre ele existentes no banco de dados, inclusive o seu histórico, cabendo ao gestor manter sistemas seguros, por telefone ou por meio eletrônico, de consulta para informar as informações de adimplemento;

III - solicitar impugnação de qualquer informação sobre ele erroneamente anotada em banco de dados e ter, em até 7 (sete) dias, sua correção ou cancelamento e comunicação aos bancos de dados com os quais ele compartilhou a informação;

VII - ter os seus dados pessoais utilizados somente de acordo com a finalidade para a qual eles foram coletados".
} 
Negativo, o art. $43, \S 1^{\circ} \mathrm{c} / \mathrm{c} \S 5^{\circ}$, do Código de Defesa do Consumidor estabelece o limite de 5 (cinco) anos para a veiculação de dados de inadimplência do consumidor. Todavia, a lei do cadastro positivo restou silente quanto à existência de qualquer prazo.

A referida omissão quanto à legitimação do direito ao esquecimento perante o cadastro positivo acaba por comprometer a própria função para qual este fora criado, pois a perpetuação da informação desatualizada restabelece a seleção adversa dos tomadores de crédito, ao desestimular potenciais investidores honestos em razão de seu histórico creditício pregresso.

Deve ser assegurada a constante atualização dos dados armazenados no cadastro positivo, de modo a propiciar uma eficiente análise do risco de crédito, assim como a garantia do livre desenvolvimento das potencialidades do possível tomador no mercado de créditos. Uma eficiente análise creditícia significará menores custos de transação e, consequentemente, melhores oportunidades de oferta de crédito com baixo custo e melhores condições pelas instituições financeiras (CAMINHA; LIMA, 2009).

Feitas as considerações acerca do arcabolço jurídico introduzido pela Lei $\mathrm{n}^{\mathbf{o}}$ 12.414/2011 e os questionamentos envolvendo os seus pontos omissos, no que tange ao exercício do direito à autodeterminação informativa no mercado de créditos, faz-se imprescindível a análise de decisão paradigmática, cujo objeto concentrou-se na aferição da compatibilidade do sistema "credit scoring" com o direito brasileiro. Apresenta-se a ementa da decisão ${ }^{7}$ em epígrafe:

RECURSO ESPECIAL REPRESENTATIVO DE CONTROVÉRSIA (ART. 543-C DO CPC). TEMA 710/STJ. DIREITO DO CONSUMIDOR. ARQUIVOS DE CRÉDITO. SISTEMA "CREDIT SCORING". COMPATIBILIDADE COM O DIREITO BRASILEIRO. LIMITES. DANO MORAL.

I - TESES: 1) O sistema "credit scoring" é um método desenvolvido para avaliação do risco de concessão de crédito, a partir de modelos estatísticos, considerando diversas variáveis, com atribuição de uma pontuação ao consumidor avaliado (nota do risco de crédito).

2) Essa prática comercial é lícita, estando autorizada pelo art. $5^{\circ}$, IV, e pelo art. $7^{\circ}, I$, da Lei n. 12.414/2011 (lei do cadastro positivo).

3) $\mathrm{Na}$ avaliação do risco de crédito, devem ser respeitados os limites estabelecidos pelo sistema de proteção do consumidor no sentido da tutela da privacidade e da máxima transparência nas relações negociais, conforme previsão do CDC e da Lei n. 12.414/2011.

4) Apesar de desnecessário o consentimento do consumidor consultado, devem ser a ele fornecidos esclarecimentos, caso solicitados, acerca das fontes dos dados considerados (histórico de crédito), bem como as informações pessoais valoradas.

\footnotetext{
${ }^{7}$ O referido entendimento foi confirmado em decisão recente, no julgamento dos EDcl no REsp 1419691/RS, Rel. Ministro LUIS FELIPE SALOMÃO, QUARTA TURMA, julgado em 18/12/2014, DJe 03/02/2015.
} 
5) O desrespeito aos limites legais na utilização do sistema "credit scoring", configurando abuso no exercício desse direito (art. 187 do CC), pode ensejar a responsabilidade objetiva e solidária do fornecedor do serviço, do responsável pelo banco de dados, da fonte e do consulente (art. 16 da Lei n. 12.414/2011) pela ocorrência de danos morais nas hipóteses de utilização de informações excessivas ou sensíveis (art. $3^{\circ}$, $\S 3^{\circ}$, I e II, da Lei n. 12.414/2011), bem como nos casos de comprovada recusa indevida de crédito pelo uso de dados incorretos ou desatualizados.

II - CASO CONCRETO: 1) Não conhecimento do agravo regimental e dos embargos declaratórios interpostos no curso do processamento do presente recurso representativo de controvérsia;

2) Inocorrência de violação ao art. 535, II, do CPC.

3) Não reconhecimento de ofensa ao art. 267, VI, e ao art. 333, II, do CPC.

4) Acolhimento da alegação de inocorrência de dano moral "in re ipsa".

5) Não reconhecimento pelas instâncias ordinárias da comprovação de recusa efetiva do crédito ao consumidor recorrido, não sendo possível afirmar a ocorrência de dano moral na espécie.

6) Demanda indenizatória improcedente.

III - NÃO CONHECIMENTO DO AGRAVO REGIMENTAL E DOS EMBARGOS DECLARATÓRIOS, E RECURSO ESPECIAL PARCIALMENTE PROVIDO.

(REsp 1419697/RS, Rel. Ministro PAULO DE TARSO SANSEVERINO, SEGUNDA SEÇÃO, julgado em 12/11/2014, DJe 17/11/2014). (grifou-se).

Verificou-se que o Superior Tribunal de Justiça, no julgamento do Recurso Especial $\mathrm{n}^{\text {o }}$ 1419697/RS, reconheceu a legalidade do sistema "credit scoring". O supracitado sistema consiste, na realidade, em um cadastro positivo de dados gerido por pessoa jurídica de direito privado, embora o STJ não o tenha enquadrado como banco de dados.

A decisão do Ministro Paulo de Tarso Sanseverino qualificou o "credit scoring" como um método de avaliação de risco de crédito, ou seja, um legítimo cadastro positivo, nos termos do art. $2^{\circ}$, I, da Lei $n^{\circ} 12.414 / 2011$, o qual atribui uma pontuação ao consumidor avaliado, com base nas informações compartilhadas. Incontestável a legalidade dessa modalidade de atividade, conforme o art. $7^{\circ}$, I, da mesma lei.

Consolidou-se o direito à autodeterminação informativa por meio de eventual responsabilização civil solidária dos responsáveis pelo tratamento dos dados, de forma objetiva e extrapatrimonial, quando as informações sensíveis forem utilizadas ou as não sensíveis forem veiculadas de modo excessivo, desatualizado ou incorreto.

A parte polêmica do aresto refere-se ao entendimento o qual é desnecessário o consentimento do consumidor consultado para a inclusão de suas informações no cadastro de avaliação de risco. Referido posicionamento foi cristalizado na Súmula 550 do STJ, de 19 de outubro de $2015^{8}$ e merece intenso debate. Afinal, como demonstrou-se anteriormente, a Lei

8 Súmula 550-STJ, in verbis: "a utilização de escore de crédito, método estatístico de avaliação de risco que não
constitui banco de dados, dispensa o consentimento do consumidor, que terá o direito de solicitar 
$\mathrm{n}^{\mathrm{o}}$ 12.414/2011 deixa expressa a necessidade de consentimento para compor qualquer cadastro positivo e, do mesmo modo, a tutela do direito à autodeterminação informativa impõe como critério basilar para o compartilhamento das informações pessoais a anuência do titular.

Na perspectiva da análise econômica do direito, quanto mais abrangente o acesso às informações mais eficiente será a avaliação do risco de crédito e consequentemente menores os custos de transação. Por isso, o supracitado posicionamento é perfeitamente justicado do ponto de vista econômico, entretanto, inconciliável com a tutela civil-constitucional da privacidade. Desse modo, a melhor solução seria a capaz de privilegiar a autonomia privada do indivíduo, quanto a decisão de ter acesso ou não ao mercado de crédito em condições privilegiadas.

Ressalta-se, por fim, como um dos principais pontos do julgamento em epígrafe a passagem em que o magistrado enfatiza a necessidade de respeito à tutela da privacidade $\mathrm{e}$ transparência das relações negociais, quando da avaliação de risco de crédito. Conciliou-se, portanto, o direito à autodeterminação informativa à metodologia da análise econômica do direito, no sentido de harmonizar os valores da personalidade do indivíduo com o desenvolvimento econômico e social, advindo de um mercado com amplo acesso ao crédito e baixas taxas de juros.

\section{CONCLUSÃO}

No contexto intitulado de Sociedade da Informação, esta se apresentou como matéria-prima da Revolução Tecnológica, assumindo papel de bem econômico e elemento estruturante das relações sociais praticadas no meio virtual. Desse modo, a noção de privacidade teve de se adaptar às novas demandas da sociedade informacional, ganhando uma feição mais dinâmica e plural, como direito à autodeterminação informativa.

O referido direito, consectário da privacidade, corresponde ao poder de controle espacial, contextual e temporal dos dados, de modo a assegurar a proteção das escolhas

esclarecimentos sobre as informações pessoais valoradas e as fontes dos dados considerados no respectivo cálculo. STJ. $2^{a}$ Seção. Aprovada em 14/10/2015, DJe 19/10/2015". 
pessoais, após certo período, momento o qual a pessoa não deseja mais ser relembrada por dados passados. Percebeu-se que a proteção dos dados pessoais, sejam eles sensíveis ou não, passou a ser o epicentro das preocupações da contemporaneidade, por isso ganhou proteção internacional.

Quando a referida problematização direciona-se ao mercado de crédito, insurge a difícil tarefa de conciliar os valores estruturantes que justificam o direito à autodeterminação informativa com a necessidade de promover o desenvolvimento econômico e a facilitação do acesso ao crédito. Afinal, de um lado colocam-se os consumidores cujos dados pessoais armazenados em bancos de dados reclamam proteção diferenciada e de outro as instituições financeiras que necessitam das informações para fazer a análise eficiente de risco na concessão do crédito.

Dessa forma, destacou-se a relevância dos bancos de dados, sob a perspectiva da análise econômica do direito, como instrumento efetivo de correção das falhas de mercado geradas pela assimetria de informações. O cadastro positivo de dados colocou-se como importante instrumento de sinalização do risco de crédito, pois a existência de um banco de dados mais completo permitiu que pessoas até então excluídas do mercado do crédito pudessem obter excelentes taxas de financiamento com base em dados simples, mas de grande valia para a análise do risco.

Ao mesmo tempo, percebeu-se que o compartilhamento das informações as quais comporão o cadastro positivo de dados deve obedecer às regras atinentes à proteção dos dados pessoais, pois a atividade de coleta desenvolvida apresenta-se como potencialmente lesiva à privacidade, especialmente quando há comercialização dos dados sem o consentimento do consumidor, exploração de dados sensíveis deste e manutenção infinita de uma anotação negativa ou até positiva.

Evidenciou-se que a adesão ao cadastro representa uma abnegação à parcela da privacidade de determinados dados, os quais poderão ser utilizados com o desiderato de oferecer melhores condições de acesso ao crédito; no entanto, não representa uma renúncia a tal direito, pois a autodeterminação informativa deverá ser observada a todo momento, com o objetivo de impedir que as informações sejam utilizadas com finalidade diversa.

Da análise da decisão do Superior Tribunal de Justiça, no julgamento do Recurso Especial $\mathrm{n}^{\mathrm{o}}$ 1419697/RS, a qual reconheceu a legalidade do sistema "credit scoring", 
destacou-se como um dos principais pontos o reconhecimento da necessidade de respeito à tutela da privacidade e à transparência das relações negociais, quando da avaliação de risco de crédito.

Conclui-se que o exercício do direito à autodeterminação informativa no mercado de créditos não se deve configurar um entrave ao bem-estar social -proporcionado pela estabilidade do sistema financeiro - fruto do fluxo informacional disponibilizado pelo cadastro positivo de dados. É perfeitamente possível e desejável a harmonização entre o binômio "informação-privacidade" aplicável à realidade do mercado de créditos, por meio de uma legislação efetiva de proteção aos dados pessoais capaz de garantir a segurança necessária ao compartilhamento de informações pelos bancos de dados, tão salutar ao desenvolvimento econômico e social do país.

\section{REFERÊNCIAS}

AZEVEDO, P. F. Organização industrial. In: PINHO, D. B.; VASCONCELLOS, M. A. S. (Org.). Manual de economia. 3. ed. São Paulo: Saraiva, 1998.

CASTELLS, Manuel. A sociedade em rede. Tradução de Roneide Venâncio Majer. 8. ed. rev. ampl. São Paulo: Paz e Terra, 2005.

BADIN, Arthur; SANTOS, Bruno Carazza dos; DAMASO, Otávio Ribeiro. Os bancos de dados de proteção ao crédito, o CDC e o PL .5870/2005: comentários sobre direito e economia. Revista de Direito do Consumidor, vol. 61, janeiro-março, 2007.

BARCELLOS, Daniela Silva Fontoura de; BARCELLOS, Tatiana Silva Fontoura de. Um balanço dos três anos de funcionamento do cadastro dos bons pagadores sob o enfoque do direito e da economia. Disponível em: <http://www.publicadireito.com.br/artigos/?cod=0841e501109ad247 > Acesso em: 29 abr. 2015. 
BARRON, John M.; STATEN, Michael. The value of comprehensive credit reports: lessons from the U.S. Experience. In: MILLER, Margaret J. (Ed.). Credit reporting systems and the international economy. London: Press Cambrigde, 2003.

BAUMAN, Zygmunt. Vida para consumo: a transformação das pessoas em mercadoria. Rio de Janeiro: Zahar, 2008.

BRAMAN, Sandra. A economia representacional e o regime global da política da informação. In Informação, conhecimento e poder: mudança e inovação social. Org. MACIEL, Maria Lucia; ALBAGAJI, Sarita. Rio de Janeiro: Garamound, 2011.

BRASIL. Constituição (1988). Constituição da República Federativa do Brasil. São Paulo: Saraiva, 2015.

Lei $\mathbf{n}^{\mathbf{0}}$ 12.414, de 09/06/2011. Disponível em: <http://www.planalto.gov.br/ccivil_03/_Ato2011-2014/2011/Lei/L12414.htm>. Acesso em 8 dez. 2015 .

.Superior Tribunal de Justiça, 2a Seção. REsp 1419697/RS, Rel. Ministro PAULO DE TARSO SANSEVERINO, j. em 12/11/2014. Disponível em: <http://stj.jusbrasil.com.br/jurisprudencia/152068666/recurso-especial-resp-1419697-rs-20130386285-0>. Acesso em: 8 dez. 2015.

CAMINHA, Uinie; LIMA, Juliana Cardoso. Poder judiciário e crédito: aplicação da teoria dos jogos. Pensar: revista de ciências jurídicas. Universidade de Fortaleza. Ano 2009, v. 14, n. 1, mês JAN/JUN, páginas 204-219.

DONEDA, Danilo. Privacidade e transparência no acesso à informação pública. Zaragoza: Prenssas Universitárias de Zaragoza, 2010. Disponível em: <http://www.egov.ufsc.br/portal/sites/default/files/lefis 11-09.pdf>. Acesso em: 28 set. 2015.

FLEISCHER, Peter. Foggy thinking about the right to oblivion. Peter Fleischer: Privacy...? $\quad$ [blog], $\quad$ mar. 2011. Disponível em: 
<http://peterfleischer.blogspot.com.br/2011/03/foggy--thinking-about-right-to-oblivion.html> Acesso em: 29 abr. 2015.

GONÇALVES, Kalline Carvalho Eler; SAMPAIO, Kelly Cristine Baião. A Garantia da Privacidade na Sociedade Tecnológica - Um imperativo à concretização do Princípio da Dignidade da Pessoa Humana. In: Direito e novas tecnologias [Recurso eletrônico on-line]. Organização CONPEDI/UNINOVE; Coordenadores: Aires José Rover, Adalberto Simão Filho, Rosalice Fidalgo Pinheiro - Florianópolis: FUNJAB, 2013.

GONÇALVES, Maria Eduarda. Direito da Informação. Coimbra: Almedina, 2003.

LASTRES, Helena Maria Martins; FERRAZ, João Carlos. In Informação e globalização na era do conhecimento. Org. LASTRES, Helena M. M.; ALBAGAJI, Sarita. Rio de Janeiro: Garamound, 2011.

LEONARDI, Marcel. Tutela e Privacidade na Internet. São Paulo: Saraiva, 2012.

MATTOS, Karla Cristina da Costa e Silva. O valor econômico da informação nas relações de consumo. São Paulo: Almedina, 2012.

MAYER-SCHÖNBERGER, Viktor. Delete: the virtue of forgetting in the digital age. New Jersey: Princeton University, 2009.

MENDES, Gilmar Ferreira. BRANCO, Paulo Gustavo. Curso de direito constitucional. São Paulo: Saraiva, 2012.

MISHIKIN, F. S. Moedas, bancos e mercados financeiros. Rio de Janeiro: LTC, 2000.

MORAES, Maria Celina Bodin de. Na medida da pessoa humana: estudos de direito civil. Rio de Janeiro: Renovar, 2010.

MURRAY, Andrew. Information tecnology law. Oxford: Oxford University Press, 2010. 
PEZELLA, Maria Cristina Cereser; GHISI, Silvano. A manipulação de dados pessoais de consumo e o sistema "crediscore". Civilistica.com, v.4, n. 1, 2015.

WARREN, Samuel Dennis; BRANDEIS, Louis Dembitz. The right to privacy. Harvard: Law Review. 1890.

RODOTÀ, Stefano. A vida na sociedade da vigilância. tradução: Danilo Doneda e Luciana Cabral Doneda. Rio de Janeiro: Renovar, 2008.

SADDI, Jairo. Crédito e judiciário no Brasil. São Paulo: Quartier Latin, 2007.

SEIDENFELD, Mark. Microeconomics Predictates to Law and Economics. Ohio: Anderson Publishing Co, 1996.

STIGLITZ, Joseph E. and WEISS, Andrew. Credit Rationing in Markets with Imperfect Information. The American Economic Review, v. 71, issue 3, 1981.

TURNER, Michael et al. A estrutura do compartilhamento de informação: Algumas considerações às vésperas da reforma brasileira do sistema de informações de crédito. Relatório Political \& Economic Research Council (PERC), 2007. 